\title{
Increasing time in outdoor environment could counteract the rising prevalence of myopia in Indian school-going children
}

\author{
Rohit Dhakal and Pavan K. Verkicharla*
}

Myopia is being seen as a serious public health concern of the 21st century due to a significant rise in its prevalence in the last few decades. Although East Asian regions are the most affected, with its prevalence rates as high as $80-90 \%$ in teenagers, the recent literature indicates a slow rise in myopia prevalence among Indian children. The combination of rapid development in digital technology (used for entertainment, playing games to learning) and the indoor-centric lifestyle such as intense/prolonged near work to strive for academic excellence and limited time in the outdoor environment may result in an epidemic of myopia in India. Studies conducted on various animal species and humans have reported a negative correlation between myopia development and increased exposure to outdoor ambient light (during day) indicating time spent outdoors as an important modifiable risk factor for myopia. In this article, we describe the current myopia scenario in India, ways to tackle the future epidemic considering the importance of day light exposure (spending time in outdoors) in counteracting myopia and reported possible public health policies for initiation at a school level that could potentially help in myopia prevention and to certain extent, control its progression.

Keywords: Myopia, outdoor environment, public health policies, school-going children.

Myopia, a serious public health concern of the 21 st century - India is emerging to play its part

MYOPIA (also known as short-sightedness) is the most common ocular condition in children and young adults in India and worldwide. It is estimated that about 2.5 billion people will be affected by myopia worldwide by this year (2020) and it will peak to nearly 5 billion by 2050 (ref. $1)$. With the worldwide increase in the prevalence of myopia in the last few decades and being associated with retinal complications irrespective of the age (even in childhood) and degree of myopia (even in cases of mild myopia $)^{2}$, the condition is being seen as a serious public health concern of the 21 st century. The development of myopia is generally irreversible with the majority of the cases due to excessive stretching of the outer coats of the eye $^{3,4}$. Its impact on individuals and society is enormous, including direct costs such as spectacles, contact lenses, refractive surgery, and indirect costs such as vision loss

The authors are in the Myopia Research Lab, Prof. Brien Holden Eye Research Center, L. V. Prasad Eye Institute, Hyderabad 500 034, India; Brien Holden Institute of Optometry and Vision Sciences, L. V. Prasad Eye Institute, Hyderabad 500 034, India.

*For correspondence. (e-mail: pavanverkicharla@lvpei.org) due to the associated ocular complications in individuals with spectacle prescription $-6.00 \mathrm{D}$ or worse $^{5-7}$. Although East Asian regions like China, Singapore and South Korea are most affected by myopia with prevalence rates as high as $80-90 \%$ in teenagers ${ }^{8}$, the prevalence of myopia in India has started to rise since a decade ${ }^{9-13}$. Sankaridurg et al. ${ }^{12}$ reported $35.5 \%$ of school-going children to have myopia in Hyderabad, Telangana, India. A retrospective analysis conducted at the L V Prasad Eye Institute, Hyderabad based on data from Indian children indicated a mean myopia progression of $-0.50 \mathrm{D} / \mathrm{yr}$, of which $17 \%$ progressed by greater than $-1.00 \mathrm{D} / \mathrm{yr}$. Based on modelling using current evidence about myopia prevalence in India, we predict that 64 million children (aged 5-15 years) living in urban regions of the country alone will have myopia by the year 2050 , if no intervention is made to counteract the same (under review: unpublished during submission of this review). It was reported that the overall prevalence of pathologic myopia ranged from $0.9 \%$ to $3.1 \%$ in Asians ${ }^{14-18}$ and about $1.2 \%$ in Caucasians ${ }^{19}$. Our work involving data from patients who visited the tertiary eye-care centres of L V Prasad Eye Institute, indicated that $4.3 \%$ of the Indian myopes had some kind of pathologic myopia lesion which is similar to what is reported in East Asian countries ${ }^{2,20}$. 


\section{Myopiogenesis and its association with ambient light exposure}

While the myopiogenesis is known to have multi-factorial contribution and various theories for myopia are being debated since centuries, the risk for myopia can be broadly classified under genetic and the environmental factors $^{21}$. Recent evidence based on research conducted on animals (experiment-based) and humans (experimentbased, epidemiological studies and randomized clinical trials) have shown associations between outdoor time and myopia, suggesting time spent outdoors as an important modifiable risk factor for myopia ${ }^{22-25}$. A study conducted in animals showed that ambient light levels (illuminance in lux) as high as 18,000-28,000 lux can retard myopia in infant monkeys, chicks ${ }^{26}$ and tree shrews ${ }^{27}$. The ambient light indoor and a typical open ground outdoor environment is found to vary significantly (by about 100 times at least $)^{28-32}$. The latest publications also indicate that time increasing spent in outdoors could also control myopia progression apart from being protective for myopia development or delaying its onset ${ }^{33-35}$. In a study conducted amongst 6-7-yr-old children of Chinese ethnicity, it was reported that the higher prevalence of myopia in Singapore was associated with less time spent outdoors compared to those living in Sydney (29.1\% prevalence $-3 \mathrm{~h} /$ week in Singapore versus $3.3 \%$ prevalence $-13.75 \mathrm{~h} /$ week in Sydney $)^{36}$. A school-based study conducted in Guangzhou among 6-7-yr-old children showed that an additional $40 \mathrm{~min}$ of outdoor activity in the intervention group $(N=952)$ for 190 days had lesser incidence of myopia compared to the control group $(N=951)(30.4 \%$ in the intervention group versus $39.5 \%$ in the control group $)^{37}$. With the increasing evidence of protective nature of time spent outdoors on myopia, various wearable light trackers are being developed to quantify light exposure and motivate children to increase their time spent outdoors (similar to the other wearable health trackers that motive for overall fitness based on the number of steps/calories burnt $)^{38}$.

There are a number of possible mechanisms by which outdoor activity could protect against the development of myopia, with the hypotheses related to activation of retinal dopaminergic system, relaxed accommodation (relaxed from prolonged reading or near task), uniform dioptric visual field (even spread of visual environment), decreased pupil size due to high illumination thereby increasing the depth of focus and reducing the blur, and exposure to specific spectral composition ${ }^{39,40}$. Of all, widely accepted factor which regulates ocular growth in outdoor illumination is the activation of retinal dopaminergic system, which in turn releases dopamine from the amacrine cells of the retina and reduces the development of myopia ${ }^{26,39,41-45}$. The other possible hypothesis relates to the interaction between different wavelengths of light (VIBGYOR), majorly red, green, blue, violet and the UV spectrum with ocular growth/myopia development. While the experiments conducted on animal models indicate that exposure to lower wavelength of light such as violet and blue could have inhibitory effects on myopia development, the role of such spectrum is still not clear in humans, and needs further study.

\section{Tackling myopia in India - need for public health policies}

The education system in India has traversed from the traditional Gurukul system where the 'Guru' (teacher) used to deliver lectures under the shade of a big tree in the outdoor-centric environment, to the modern world schools where students are delivered education under a roof in an indoor-centric environment with the use of modern technologies such as projectors, tablets and laptops being in the race with rapidly advancing science and technology. The combination of rapid development in digital technology (used for entertainment, playing games to learning) and the indoor-centric lifestyle such as prolonged near work to strive for academic excellence and limited time in the outdoor environment may result in an epidemic of high myopia in India. The increasing figures of myopia prevalence in the current generation of schoolgoing children in urban regions of India and being the home of the second highest population in the world, India is at a high risk for reaping myopic and high myopic population by 2050 , if the necessary public health policies are not implemented to counteract the same. Given the potential role of spending more time in an outdoor environment in myopia prevention, India needs to develop public health policies to encourage children to increase their time outdoors to counteract the increasing myopia prevalence, similar to the initiatives taken by the governments in East Asian countries.

Intense educational pressure from the family and teachers to achieve academic excellence, excessive homework, use of gadgets to accomplish school tasks, after-school tuition and classes for extracurricular activities such as drawing, music, dance, etc. are predominantly indoor-centric activities that limit the time for children to spend in outdoors. Given that myopia develops during childhood, and that children spend most of their daytime in school, it is important that myopia-related policies need to be implemented strictly at the school level, wherever applicable.

The public health policies are largely driven by local cultural belief, lifestyle and environment, which makes it difficult to implement similar policies all over the world. However, there are obviously some learnings from the initiatives taken by countries in East Asia to decrease the incidence and progression of myopia. For example, Singapore initiated 'Kids for Nature' programme in collaboration with National Parks to educate primary school children and their parents on ways to spend time with 
nature by doing various outdoor activities. While in China and Taiwan, a few schools have implemented mandatory recess/break time of 40-80 min, where children are supposed to be in the outdoor environment ${ }^{37}$, a few have developed bright classrooms that provide ambient light to children, which started to show an impact in controlling myopia incidence and progression ${ }^{46,47}$. Reducing the amount of homework, increasing the amount of recess time, locking the classrooms during recess time to keep children outdoors, the concept of bright classrooms (average illuminance at desk $>500$ lux) have been attempted in Taiwan and China, and reported to be effective in reducing the onset and progression of myopia ${ }^{37,48,49}$.

\section{Possible public health policies for initiation}

While the policymakers at the State and Central Government levels are majorly responsible for this, equally responsible are the eye-care professionals (specially optometrists and ophthalmologists in educating and creating awareness about the potential role of time outdoors in myopia prevention), and other stakeholders at the ground level such as principals, teachers, parents and children to work together to stop this future epidemic in India. Here are some of the policies that the Indian Government can implement to prevent myopia onset and progression in the country.

(1) Mandatory $1 \mathrm{~h}$ (60 min) of recess time in all schools during the school hours every day (locking the classrooms during recess time to keep children outdoors), right from the primary school level.

(2) Recommend all educational institutions (especially primary and secondary schools) to have a structured recess time incorporated into the curriculum.

(3) Make it mandatory for schools to have enough space for playgrounds.

(4) Advice for new/upcoming schools to construct classrooms with more windows, so that they are well lit and receive sufficient natural light (taking into consideration of illuminance).

(5) Create public awareness among parents about the importance of outdoor time using different media (issued in public interest).

(6) Recommend/promote community centres in each locality to organize outdoor programmes at least twice a month on weekends.

(7) Promote/train/educate various stakeholders (principals, teachers, parents and children) about the importance of exposure to ambient light/increasing time outdoors for better health, apart from its role in countering myopia.

Disclosure: The authors report no conflicts of interest and have no proprietary interest in any of the materials mentioned in this article.
1. Holden, B. A. et al., Global prevalence of myopia and high myopia and temporal trends from 2000 through 2050. Ophthalmology, 2016, 123(5), 1036-1042.

2. Dhakal, R., Goud, A., Narayanan, R. and Verkicharla, P. K., Patterns of posterior ocular complications in myopic eyes of Indian population. Sci. Rep., 2018, 8(1), 13700.

3. McBrien, N. A., Cornell, L. M. and Gentle, A., Structural and ultrastructural changes to the sclera in a mammalian model of high myopia. Invest. Ophthalmol. Vis. Sci., 2001, 42(10), 2179-2187.

4. Rada, J. A. S., Shelton, S. and Norton, T. T., The sclera and myopia. Exp. Eye Res., 2006, 82(2), 185-200.

5. Wong, T. Y., Foster, P. J., Johnson, G. J. and Seah, S. K., Refractive errors, axial ocular dimensions, and age-related cataracts: the Tanjong Pagar survey. Invest. Ophthalmol. Vis. Sci., 2003, 44(4), 1479-1485.

6. Lim, M., Gazzard, G., Sim, E., Tong, L. and Saw, S., Direct costs of myopia in Singapore. Eye, 2009, 23(5), 1086.

7. Saw, S. M., Gazzard, G., Shih-Yen, E. C. and Chua, W. H., Myopia and associated pathological complications. Ophthal. Physiol. Opt., 2005, 25(5), 381-391.

8. Jung, S.-K., Lee, J. H., Kakizaki, H. and Jee, D., Prevalence of myopia and its association with body stature and educational level in 19-year-old male conscripts in Seoul, South Korea. Invest. Ophthalmol. Vis. Sci., 2012, 53(9), 5579-5583.

9. Singh, N. K., James, R. M., Yadav, A., Kumar, R., Asthana, S. and Labani, S., Prevalence of myopia and associated risk factors in schoolchildren in North India. Optom. Vis. Sci., 2019, 96(3), 200-205.

10. Sheeladevi, S., Seelam, B., Nukella, P. B., Modi, A., Ali, R. and Keay, L., Prevalence of refractive errors in children in India: a systematic review. Clin. Exp. Optom., 2018, 101(4), 495-503.

11. Saxena, R., Vashist, P., Tandon, R., Pandey, R. M., Bhardawaj, A., Menon, V. and Mani, K., Prevalence of myopia and its risk factors in urban school children in Delhi: the North India Myopia Study (NIM Study). PLOS ONE, 2015, 10(2), e0117349e0117349.

12. Sankaridurg, P., Philip, K., Konda, N., Kanduri, S., Siddireddy, S. and Holden, B. A., Prevalence of refractive errors in urban schoolchildren in India: the Hyderabad Eye Study. Invest. Ophthalmol. Vis. Sci., 2015, 56(7), 2936.

13. Singh, N. K., James, R. M., Yadav, A., Kumar, R., Asthana, S. and Labani, S., Prevalence of myopia and associated risk factors in schoolchildren in North India. Optom. Vis. Sci., 2019, 96(3), 200-205.

14. Asakuma, T. et al., Prevalence and risk factors for myopic retinopathy in a Japanese population: the Hisayama Study. Ophthalmology, 2012, 119(9), 1760-1765.

15. Chang, L. et al., Myopia-related fundus changes in Singapore adults with high myopia. Am. J. Ophthalmol., 2013, 155(6), 991-999.

16. Chen, S. J., Cheng, C. Y., Li, A. F., Peng, K. L., Chou, P. Chiou, S. H. and Hsu, W. M., Prevalence and associated risk factors of myopic maculopathy in elderly Chinese: the Shihpai eye study. Invest. Ophthalmol. Vis. Sci., 2012, 53(8), 4868-4873.

17. Gao, L. Q. et al., Prevalence and characteristics of myopic retinopathy in a rural Chinese adult population: the Handan Eye Study. Arch. Ophthalmol., 2011, 129(9), 1199-1204.

18. Liu, H. H., Xu, L., Wang, Y. X., Wang, S., You, Q. S. and Jonas, J. B., Prevalence and progression of myopic retinopathy in Chinese adults: the Beijing Eye Study. Ophthalmology, 2010, 117(9), $1763-1768$

19. Attebo, K., Ivers, R. Q. and Mitchell, P., Refractive errors in an older population: the Blue Mountains Eye Study. Ophthalmology, 1999, 106(6), 1066-1072.

20. Verkicharla, P. K., Ohno-Matsui, K. and Saw, S. M., Current and predicted demographics of high myopia and an update of its associated pathological changes. Ophthal. Physiol. Opt., 2015, 35(5), 465-475. 
21. Chakraborty, R., Ostrin, L. A., Benavente-Perez, A. and Verkicharla, P. K., Optical mechanisms regulating emmetropisation and refractive errors: evidence from animal models. Clin. Exp. Optom., 2020, 103(1), 55-67.

22. Rose, K. A., Morgan, I. G., Ip, J., Kifley, A., Huynh, S., Smith, W. and Mitchell, P., Outdoor activity reduces the prevalence of myopia in children. Ophthalmology, 2008, 115(8), 1279-1285.

23. French, A. N., Morgan, I. G., Mitchell, P. and Rose, K. A., Patterns of myopigenic activities with age, gender and ethnicity in Sydney schoolchildren. Ophthal. Physiol. Opt., 2013, 33(3), 318-328.

24. Lin, Z. et al., Near work, outdoor activity, and their association with refractive error. Optom. Vis. Sci., 2014, 91(4), 376-382.

25. Guo, Y. et al., Myopic shift and outdoor activity among primary school children: one-year follow-up study in Beijing. PLoS ONE, 2013, 8(9), e 75260.

26. Ashby, R., Ohlendorf, A. and Schaeffel, F., The effect of ambient illuminance on the development of deprivation myopia in chicks. Invest. Ophthalmol. Vis. Sci., 2009, 50(11), 5348-5354.

27. Siegwart Jr, J. T., Ward, A. H. and Norton, T. T., Moderately elevated fluorescent light levels slow form deprivation and minus lens-induced myopia development in tree shrews. Invest. Ophthalmol. Vis. Sci., 2012, 53(14), 3457.

28. Read, S. A., Collins, M. J. and Vincent, S. J., Light exposure and physical activity in myopic and emmetropic children. Optom. Vis. Sci., 2014, 91(3), 330-341.

29. Read, S. A., Collins, M. J. and Vincent, S. J., Light exposure and eye growth in childhood. Invest. Ophthalmol. Vis. Sci., 2015, 56(11), 6779-6787.

30. Wen, L. et al., Objectively measured near work, outdoor exposure and myopia in children. Br. J. Ophthalmol., 2020, Epub ahead of print.

31. Alvarez, A. A. and Wildsoet, C. F., Quantifying light exposure patterns in young adult students. J. Mod. Opt., 2013, 60(14), 1200-1208.

32. Dharani, R. et al., Comparison of measurements of time outdoors and light levels as risk factors for myopia in young Singapore children. Eye (London), 2012, 26(7), 911-918.

33. Ho, C. L., Wu, W. F. and Liou, Y. M., Dose-response relationship of outdoor exposure and myopia indicators: a systematic review and meta-analysis of various research methods. Int. J. Environ. Res. Public Health, 2019, 16(14), 2595.

34. Sherwin, J. C., Reacher, M. H., Keogh, R. H., Khawaja, A. P., Mackey, D. A. and Foster, P. J., The association between time spent outdoors and myopia in children and adolescents: a systematic review and meta-analysis. Ophthalmology, 2012, 119(10), $2141-2151$.

35. Xiong, S. et al., Time spent in outdoor activities in relation to myopia prevention and control: a meta-analysis and systematic review. Acta Ophthalmol., 2017, 95(6), 551-566.

36. Rose, K. A., Morgan, I. G., Smith, W., Burlutsky, G., Mitchell, P. and Saw, S.-M., Myopia, lifestyle, and schooling in students of Chinese ethnicity in Singapore and Sydney. Arch. Ophthalmol., 2008, 126(4), 527-530.
37. He, M. et al., Effect of time spent outdoors at school on the development of myopia among children in China: a randomized clinical trial. JAMA, 2015, 314(11), 1142-1148.

38. Wang, J., He, X.-G. and Xu, X., The measurement of time spent outdoors in child myopia research: a systematic review. Int. J. Ophthalmol., 2018, 11(6), 1045.

39. Norton, T. T. and Siegwart Jr, J. T., Light levels, refractive development, and myopia - a speculative review. Exp. Eye Res., 2013, 114, 48-57.

40. Dolgin, E., The myopia boom. Nature, 2015, 519(7543), 276278.

41. Stone, R. A., Lin, T., Laties, A. M. and Iuvone, P. M., Retinal dopamine and form-deprivation myopia. Proc. Natl. Acad. Sci. USA, 1989, 86(2), 704-706.

42. Ashby, R. S. and Schaeffel, F., The effect of bright light on lens compensation in chicks. Invest. Ophthalmol. Vis. Sci., 2010, 51(10), 5247-5253.

43. Smith 3rd, E. L., Hung, L. F. and Huang, J., Protective effects of high ambient lighting on the development of form-deprivation myopia in rhesus monkeys. Invest. Ophthalmol. Vis. Sci., 2012, 53(1), 421-428.

44. Foulds, W. S., Barathi, V. A. and Luu, C. D., Progressive myopia or hyperopia can be induced in chicks and reversed by manipulation of the chromaticity of ambient light. Invest. Ophthalmol. Vis. Sci., 2013, 54(13), 8004-8012.

45. Cohen, Y., Belkin, M., Yehezkel, O., Solomon, A. S. and Polat, U., Dependency between light intensity and refractive development under light-dark cycles. Exp. Eye Res., 2011, 92(1), $40-46$.

46. Zhou, Z. et al., Pilot study of a novel classroom designed to prevent myopia by increasing children's exposure to outdoor light. PLoS ONE, 2017, 12(7), e0181772.

47. Winterbottom, M. and Wilkins, A., Lighting and discomfort in the classroom. J. Environ. Psychol., 2009, 29(1), 63-75.

48. Wu, P.-C., Tsai, C.-L., Wu, H.-L., Yang, Y.-H. and Kuo, H.-K., Outdoor activity during class recess reduces myopia onset and progression in school children. Ophthalmology, 2013, 120(5), 1080-1085.

49. Hua, W. J., Jin, J. X., Wu, X. Y., Yang, J. W., Jiang, X., Gao, G. P. and Tao, F. B., Elevated light levels in schools have a protective effect on myopia. Ophthal. Physiol. Opt., 2015, 35(3), 252262 .

ACKNOWLEDGMENT. The authors acknowledge the support of the Hyderabad Eye Research Foundation to the Myopia Research Lab and its activities at LVPEI.

Received and accepted 18 September 2020

doi: $10.18520 / \mathrm{cs} / \mathrm{v} 119 / \mathrm{i} 10 / 1616-1619$ 